\title{
Fotografía experimental en España. La obra de Luisa Rojo, intervención y abstracción
}

\section{Experimental photography in Spain. The work of Luisa Rojo, intervention and abstraction}

\author{
Mónica Carabias Álvaro \\ Profesora Ayudante Doctor. Departamento Arte III. Facultad de Geografía e Historia \\ monicacarabias@telefonica.net
}

Recibido: 2 de diciembre de 2011

Aprobado: 6 de febrero de 2012

\section{Resumen}

Luisa Rojo (Cetina, Zaragoza, 1946) está considerada pionera del Copy Art y del Cibachrome en España. Su interés por la imagen femenina, la fotocopia y el color se suman a la utilización de medios de naturaleza cambiante y potencialmente abstracta. Todo ello da como resultado unas imágenes que transgreden los límites de la fotografía tradicional, y plantean un diálogo constante y equilibrado entre la forma y el contenido.

Palabras Clave: Copy Art, Arte Pop, fotografía experimental, España, mujeres.

Carabias Álvaro, M. (2012): Fotografía experimental en España. La obra de Luisa Rojo, intervención y abstraccións. Arte, Individuo y Sociedad, 24(2) 227-249

\begin{abstract}
Luisa Rojo (Cetina, Zaragoza, 1946) is considered to be pioneer of the Copy Art and the Cibachrome in Spain. Her interest in the female image, photocopy and color join the use of means of changing and potentially abstract nature. All this has resulted in a few images that violate the boundaries of traditional photography, and pose a constant and balanced dialogue between the form and content.

Key Words: Copy Art, Pop Art, experimental photography, Spain, women.
\end{abstract}

Carabias Álvaro, M. (2012): Experimental photography in Spain. The work of Luisa Rojo, intervention and abstraction. Arte, Individuo y Sociedad, 24(2) 227-249

Sumario: 1. Introducción, 2. Objetivo, 3. Metodología, 4. Biografía, 5. Recorrido por la obra (fotografía experimental) y exposiciones, 6. Conclusiones, 7. Glosario. Referencias.

Este artículo recoge los resultados de la investigación realizada en el marco del proyecto "Tras la República: redes y caminos de ida y vuelta en el arte español desde 1931". PN I+D+i 2012-2014.

Referencia: HAR2011-25864 


\section{Introducción}

"Ahora, al fin de siglo, después que la Bauhaus fusionara las Bellas con las aplicadas artes, la fotografía pasó en el fin de milenio a ser la reina de las artes. Como la energía, es lo más directo, próximo, lejano, inasible, captable, como la luz y los pensamientos, que radican en la intuición, sueños en soporte brillante, frágiles como el papel y efimeras como un momento de luz en la retina del tiempo" (ROJO, 1994: 80).

La trayectoria artística de Luisa Rojo representa una defensa férrea del arte y la reflexión. Pionera del Copy Art y del Cibachrome en España ha sabido trazar una obra atenta, como ninguna otra, a la naturaleza potencialmente cambiante de los medios y en la que se aprecia un interés manifiesto por la imagen femenina. Hacia el año 1967 inicia su idilio con la fotografía y la experimentación. Empezó trabajando con el blanco y negro retratando paisajes, lugares, niños, mujeres. Estos dos últimos motivos, pronto se iban a convertir en los dos más redundantes a largo de su producción. Poco después comenzaría con el color. Lo importante es que, independientemente del uso del color o del blanco y negro, será en esta fecha cuando siente las bases de su estilo, al tiempo que despierte el eterno interés por el trío que forman: técnica, proceso y resultado.

Luisa Rojo afirma, con la rotundidad más absoluta de la que ella sólo es capaz, que las técnicas y los procedimientos no le apasionan, que son meros instrumentos útiles en la medida en que le permiten lograr lo que una/o quiere: "Romperme la cabeza por la técnica no me la he roto, es más, creo que la destrozo una vez que consigo lo que quiero. Paso total y absolutamente de ella. Si quiero lograr una ruptura total de luces y llegar a tal punto para conseguir la imagen que tengo en la cabeza, rompo lo que tenga que romper" (ROJO, 2011).

\section{Objetivo}

El presente estudio aborda la contribución de Luisa Rojo en el desarrollo y evolución de la fotografía española desde las últimas tres décadas, coincidiendo con la llegada del régimen democrático en nuestro país. Sin duda alguna, entre sus principales aportaciones al desarrollo del arte fotográfico se encuentran, por un lado, el trabajo desarrollado en el campo de la investigación de los sistemas de impresión, siendo una de las artistas pioneras en el uso del Copy Art y del Cibachrome en España. En este sentido, cabe destacar que la peculiaridad de esta creadora reside, precisamente, en utilizar el medio técnico, antes que nada, como un instrumento eficaz en su afán por retratar la esencia fugaz de las cosas y expresar la experiencia de las emociones. Y por otro lado, el protagonismo e importancia que concede a la representación de la imagen femenina. Sin olvidar, la particularidad de realizar obra única.

\section{Metodología}

Este texto ha sido realizado a partir de las numerosas entrevistas mantenidas con la artista a lo largo del 2011 en su estudio de Cetina, Zaragoza y en Madrid. Para 
su elaboración se han consultado el archivo personal y los trabajos originales de la autora, así como los catálogos de sus exposiciones colectivas e individuales, las reseñas expositivas y artículos de prensa. La selección de los trabajos expuestos en este artículo se ha realizado en función de: a) La relevancia de su carácter experimental b) La evolución de la temática c) Las impresiones revisadas de la artista con respecto a la selección planteada.

El análisis de las obras expuestas en este artículo se ha desarrollado a partir de los comentarios y reflexiones que tuvieron lugar durante las varias entrevistas y son, igualmente, resultado de mi experiencia directa con la obra original y el resto de material y herramientas habituales en el trabajo de Luisa Rojo. Por último, comentar que para esta exposición y análisis de fotografías se ha respetado la narración cronológica y descriptiva desarrollada durante la entrevista.

\section{Biografía}

María Luisa Rojo Gayán, Luisa Rojo, nace en Cetina, Zaragoza, en 1946. Su espíritu inquieto al igual que inconformista le lleva a consolidar una formación académica multidisciplinar: diplomada en Enfermería (Universidad de Zaragoza 19641967), Relaciones Públicas (Cámara de Comercio e Industria de Madrid 1988), Artes Decorativas y Diseño (Madrid 1969), Confección de Sombreros (Escuela de Diseño "ARTYMODA", Madrid 1989), Escuela de Cerámica (Taller Tanagra, Madrid 1970). Sobre lo cual añadir, entre otros, un intercambio cultural en la Foreing Study League (Baltimore, USA 1971), el Curso de Dirección y Dinámica de grupos (1973), varios cursos de cine sobre guión y práctica de la imagen fílmica (Universidad de Verano, Teruel 1985 y 1986 respectivamente) y de Cultura Islámica en Aragón (Teruel, 1988). Todo ello reflejo de su posterior y larga trayectoria profesional.

En 1967 comienza a trabajar con la fotografía y lo hace con una cámara Olimpus comprada en Canarias. Es seleccionada para participar en el taller de fotografía impartido por el checoslovaco Jan Saudek, "Gente fotografía gente" y en el Seminario de Cine -un medio que le apasiona- realizado por Fernando Trueba; ambos celebrados en el Círculo de Bellas Artes de Madrid (1992). A partir de 1989, amplía su trayectoria fotográfica al campo de la docencia e imparte varios talleres de fotografía: "La visión intensiva" (Tarazona Foto, 1989), "Expresión plástico/gráfica" (Escuela de Arte, Universidad de Oviedo, 1989), "El estilismo, estética e iluminación en fotografía" (Sociedad Fotográfica de Vitoria, 1987), "La Polaroid" (Universidad de Oviedo y Sociedad Fotográfica de Vitoria, 1990), "Lo útil del arte" (Zaragoza, 1990). Su trabajo ha sido publicado en prensa -El País, Diario 16, Córdoba, ABC, Arte Fotográfico, El Heraldo de Aragón, FV, etc.- y expuesto de forma individual y/o colectiva ininterrumpidamente en galerías, museos, ferias de arte y festivales de fotografía desde el año 1977. Su obra se encuentra en colecciones públicas y privadas

Ha realizado numerosos estilismos para empresas -SEAT, Kodak, Polaroid- y revistas -Foto Profesional, FV, Información Profesional-. 


\section{Recorrido por la obra (fotografía experimental) y exposiciones}

A finales de 1967, Luisa Rojo termina los estudios de Enfermería en la capital aragonesa y se traslada a Barcelona, donde permanece año y medio. Desde aquí parte a Madrid para instalarse definitivamente. Era el año 1969. Su llegada a la capital va a representar el comienzo de su formación artística y fotográfica, así como de una producción intensa y prolífica: "En los principios, la verdad es que tenía claro lo que quería contar y buscaba los medios para hacerlo. Pero no fue nunca fácil y ahora tampoco" (ROJO, 2011). A comienzos de 1970, toma clases en el Taller Tanagra de la calle Jorge Juan hasta que inicia los estudios oficiales en la Escuela de Artes Decorativas, ubicada en la calle Salustiano Olozaga. Después, ya avanzada la década de los setenta, continúa su formación asistiendo, asiduamente, a los cursos celebrados en el Taller Villalar; como el dedicado a los esmaltes en cerámica (1975). Su galerista y amigo Julio Álvarez Sotos (1990: 4-5) señalaba, precisamente, la formación que esta artista adquiere en Madrid y México de las nuevas formas de expresión de la cerámica, y su capacidad para transformar las clásicas vasijas y recipientes en sorprendentes objetos -bolsas de compra, trozos de tubería...- con una diversidad de texturas y ricos en todo tipo de cromatismos y colores.

"Villalar me revolucionó mucho" (ROJO, 2011), confiesa Luisa. Era un espacio cultural ubicado en la misma calle Villalar donde de forma regular, además de cursos, se organizaban reuniones de arte, se debatía acerca de la actualidad política, la música..., y, curiosamente, allí pudo verse por vez primera en España una actuación del artista Llorens Barber. Luisa Rojo contactó en este centro con el mundo del arte en general. Entre sus mejores recuerdos vinculados a Villalar, menciona el haber conocido a Óscar García Benedí (1952-1990). Este pintor manchego fue uno de los primeros artistas que al igual que ella utilizaron el trabajo electrográfico -la fotocopia- como soporte artístico. Falleció en Madrid a la temprana edad de 38 años. Con su obra Piano, pintada al revés para que sólo pudiera verse a través de un espejo, obtuvo la Medalla de Bronce de Pintura de la XVI Bienal de Alejandría (1987). Comenta Luisa lo mucho que le impresionaron las reproducciones que este joven artista había realizado a partir de una serie de dibujos sobre toreros, especialmente, por la forma tan personal con la que trataba y aplicaba el color. En el taller, también coincidiría con el experto en color e imagen Juan Carlos Sanz, asistiendo al curso que impartió sobre la Sinestesia y el Color (1981): "Aprendí mucho y me sirvió para poder convertir las sensaciones al papel" (ROJO, 2011). Este mismo año participaría en la exposición "Cerámica y fotografía" organizada por el Taller, cuyo cartel anunciador hizo Óscar García Benedí. Luisa expuso un collage con fotocopias de 2x2 metros en el que llamaba la atención la grafía lúdica y dinámica que había logrado incorporando a la obra los diseños de Letraset.

Unos cuantos años atrás, en 1977, Luisa Rojo preparó, junto al también fotógrafo y marido en aquel entonces Valentín Sama, uno de los primeros Cibachrome de España en su laboratorio de la calle Juan Ramón Jiménez, n² 22. Se realizó con el kit que la pareja había comprado en un viaje a Suiza y con el que sólo podían realizarse copias no superiores a un tamaño de $40 \times 50 \mathrm{cms}$. El resultado del trabajo realizado por Sama y Rojo con este nuevo procedimiento fue expuesto por primera vez en la Galería Spectrum de Zaragoza (1977) -la primera galería dedicada exclusivamente 
a la promoción y divulgación de la fotografía de vanguardia inaugurada en 1977-, y un año después en la Spectrum Canon de Barcelona. En la exposición se pudo ver un conjunto de imágenes cuyo núcleo central residía en la ciudad y el paisaje, y donde la presencia humana se había eliminado de forma consciente. Luisa expuso una serie de fotografías analógicas de $30 \times 40$ y $40 \times 50 \mathrm{cms}$, procesadas posteriormente en Cibachrome, donde se planteaba un discurso lúdico a partir de la significación de ciertos objetos cotidianos: "Cosas ocasionales, como colillas, que me iba encontrando cuando caminaba por la playa o la ciudad. No tenía una idea preconcebida. Hacia fotos de composiciones o de imágenes que se me fijaban en la cabeza y que por la óptica me parecían interesantes" (ROJO, 2011). En estas primeras imágenes, procesadas con una técnica impecable, ya quedaba reflejado en la artista aragonesa el sentido de ruptura ligado al proceso de intervención, que eclosionaría con fuerza unos años después. Inauguraba así un proceso de investigación centrado primero, en el uso de los colores contrastados, y segundo, en su interés por el ser humano, que jamás desaparecerá de su obra, junto al entorno que le rodea, especialmente la ciudad.

De esta manera, Luisa Rojo emprende una etapa (1976-1987) en la que el individuo se representa en el más estricto anonimato. En un estado de soledad derivado de los trágicos efectos de la deshumanización. Dos años después, expone la serie fotográfica que realizó en Cabo de Gata (Spectrum, Zaragoza 1979). Las imágenes fueron construidas a partir de una geometría visual muy personal: en el centro colocó un trapo y detrás de este emergía el retrato de una joven gitana. La artista establecía así una correspondencia anímica entre el estado de soledad y el deseo formal por salirse del espacio, de los huecos convencionales fijados por la superficie del papel. Además de romper frontalmente con el color y de manipular de forma ilimitada el blanco y negro. Todo ello le llevaba inevitablemente a emprender un viaje sin límite por el mundo de la abstracción y del gesto.

En 1980, su relación con Oscar García Benedí le introdujo de lleno en el mundo del Copy Art, en España conocido como arte de la fotocopia. Era frecuente encontrarles experimentando con las máquinas fotocopiadoras en el establecimiento que Rank Xerox tenía en la calle Rosales: "Una y otra vez dábamos la lata a los técnicos para que nos permitieran manipular, tocar y mover las imágenes procesadas con la máquina fotocopiadora" (ROJO, 2011). En este centro, Luisa realizó sus primeros trabajos con fotocopias a partir de unas fotografías de gestos y de gente andando que había tomado en la calle. Estas imágenes analógicas eran primero positivadas, después fotocopiadas y, por último, intervenidas de forma muy diversa pintándolas, cortándolas..: "La fotocopia rompía, se salía de la medida, explica Luisa, además, con las luces hacía lo que quería. Jugaba y forzaba las tomas hasta el límite. Luego volvía a reproducir la fotografía, porque las galerías querían soporte fotográfico para poder exponer" (ROJO, 2011). El resultado de todo este proceso novedoso y experimental fue expuesto en la galería Redor de Madrid (1980) y en las ciudades de Bilbao, Arlés y Barcelona.

La artista aragonesa encontró en las fotocopias el medio con el que forzar el movimiento de la imagen. El arte de la fotocopia representaba fugacidad, fragilidad, mestizaje, ritmo. Todo eso y mucho más deseba esta artista. La fotocopia era un trozo de papel convertido en soporte artístico en el que todo valía, cuya fuerza radicaba 
en gran parte en su inmediatez. Pero sobre todo muy atractivo para los artistas de la manipulación y la experimentación como Luisa Rojo, principalmente, por dos de sus cualidades esenciales: la primera, el precio, era muy barata, y la segunda, el tiempo de re/producción era muy rápido, casi inmediato.

El Copy Art irrumpió en España de forma tardía y lo hizo suscitando mucha reticencia entre los distintos campos de la creación. Sin embargo, hubo unos cuantos artistas que supieron ver las posibilidades que la fotocopia en cuanto al tamaño, color, materiales o papeles brindaba a la creación e innovación artística en general. Las fotocopias pasaron por ser "útiles de trabajo" como, por ejemplo, reconocía el diseñador José Luís Tirado, un instrumento más con el que conseguir diversos resultados y distanciarse del método pictórico; una forma de ensayar y encontrar colores y casualidades en el caso de Luís Gordillo, o el soporte básico para la creación como en el artista catalán Pere Noguera, uno de los creadores que más experimentaría con el Copy Art. Éste convirtió, definitivamente, a la fotocopia en un medio de expresión artística autónoma e independiente. Expuso su trabajo sobre las metamorfosis de diversos objetos por acción de la oxidación en "Metronom", una galería de Barcelona fundada por Rafael Tous, que se dedicaba a las artes marginales y que fue clausurada en 1984; en ella se había expuesto un trabajo colectivo en vivo realizado con fotocopias por los alumnos de la Escuela Elisava.

Por el año 1983, Luisa Rojo se encontraba inmersa de lleno en la manipulación de la imagen y las fotocopias. Las posibilidades que le brindaban eran muchas, pese a las objeciones puestas por los puristas a este tipo de trabajos, incluidos los propios fotógrafos. A lo largo de este año preparó la exposición "M-30" (galería Moriarty, Madrid, 1983 y Spectrum, Zaragoza, 1984), en la que participó junto al pintor Pablo Márquez.

La escasa tecnología y la dificultad para encontrar fotocopiadoras en color de alta calidad redujeron considerablemente los límites y posibilidades que brindaba inicialmente, y afectó irremediablemente a su implantación, extensión y consolidación en España, como declaraba Gabriela Cañas (1984: 41) en un artículo a propósito de la exposición "M-30". Asimismo, recalcaba que habían sido muy pocos los que, se habían adentrado en este terreno. De hecho, esta muestra era la tercera protagonizada por artistas que experimentaban con la nueva estética de las fotocopias. La razón, explicaba Cañas, no era un problema de estrechez ideológica, sino una limitación técnica. En España resultaba muy difícil encontrar fotocopiadoras en color que permitieran reproducciones de alta calidad.

Luisa estuvo preparando este proyecto a pie de calle y convirtió a la fotocopia en el personaje principal. En el proceso que respondía mejor que ningún otro a su entusiasmo por alterar las imágenes. Fijó su mirada nuevamente en la gente y el espacio urbano de la ciudad, retratando, incluso, atropellos y muertes en las calles. En realidad, este trabajo había comenzado casi dos años antes con las imágenes de gestos y gente en la ciudad que había expuesto en la muestra "Artistas para la libertad" (Centro Cultural de la Villa de Madrid, 1982). El trabajo para "M-30" fue expuesto a modo de collage y realizado con Cibachromes fotocopiados a blanco y negro y montados sobre un cartón gris de $2 \times 3$ metros. 
El componente lúdico estaba, indefectiblemente, asociado al Copy Art, lo mismo que la técnica del collage, dado que permitía a la artista jugar ilimitadamente con las imágenes y la fotografía. Con este trabajo Rojo afianzaba sus intereses artísticos y lograba representar con crudeza las experiencias y las sensaciones en la relación, a veces trágica e inevitable, entre la ciudad y el hombre. La fotocopia junto al rotulador, la acuarela y la fotografía fueron suficientes para que ésta y el pintor Pablo Márquez retrataran, individualmente, la fisonomía derivada del asfalto y la calle: “(...)No importa, explicaba Pablo Márquez (1984), tanto si vence el asfalto o la vegetación invade tímidamente al ciudad. En cualquier caso, el hombre convive con ambos y es capaz, aún con ánimo de crítica, de hallar sus valores estéticos y de mostrarlos...". Además, ambos creadores dieron un paso más. El hecho de que una fotocopia costara dos pesetas significaba una decidida apuesta por la necesidad del abaratamiento del arte. Pablo Márquez declaró: “(...)de cada original expuesto en la muestra hacemos una carpeta con fotocopias retocadas, trabajadas, sobre el mismo tema. Cada una puede ser adquirida por 1.500 ó 2.000 pesetas" (MÁRQUEZ, 1984).

Poco después, Luisa participó en la muestra "Cinco fotógrafos del color" (galería F. de Atenas, Grecia, 1984). En esta ocasión, expuso imágenes abstractas de ruptura a media imagen, Cibachromes de colores primarios muy lavados e imágenes heliográficas sobre gestos de mujeres. Era la primera vez en la que la imagen de la mujer se convertía en la protagonista única de su obra. Recurría para ello a una gramática visual muy transgresora con los materiales, y a unas obras de gran tamaño, $2 \times 4$ metros, reproducidas en un plotter de arquitecto sobre papel Milar y colgadas del techo de la sala a media altura. Todo ello reforzaba la reflexión personal de la artista con respecto al sentido trascendental de ser mujer en el mundo y el papel esencial que ésta desempeña en cuanto a la misión de transmisión de valores y herencia cultural: "Nunca he retratado a la mujer mostrando sus penurias. He querido representarla en todos los ámbitos, pero nunca como una imagen lastimera sino como Mujer con mayúscula, aunque algunas veces tratara un tema penoso" (ROJO, 2011). En realidad, esta actitud de exponer los temas sin una crudeza explícita es una constante en su trayectoria: "Cuando monto una exposición y cuento una historia me gusta ser respetuosa. Y mostrar lo que quiero, así como abrazándoles, dándoles cariño y amor para que entren en lo que cuento y se lo lleven puesto en la cabeza" (ROJO, 2011). Pablo Márquez comentaba algo parecido a estas palabras de la artista con motivo de Besos (1993): "Luisa nunca nos ha golpeado. Su vida, como la de todos ha pasado por momentos difíciles pero ni en los de mayor debilidad cuando a veces el arte nos sirve como descarga de la amargura que llevamos dentro, ella nunca se ha permitido ese gesto, de egoísmo, por el cual nos hubiera trasladado sus fantasmas y esto nunca ha sido así por un ejercicio de disciplina sino como algo que brotaba de ella inconscientemente..." (MÁRQUEZ, 1993: 4).

Atrapada en el proceso de manipulación de imágenes generadas, entre otros, por las máquinas fotocopiadoras participa en la muestra colectiva "Procesos. Cultura y Nuevas Tecnologías" con la que se inauguraba en 1986 el MNACRS, en aquel entonces Centro de Arte Reina Sofía. Estuvieron invitados por Marisa González, comisaria del apartado de Electrografía y participante en la misma con la obra Metamorfosis. Naciendo, una pintura a la luz de materiales orgánicos transformados con fotocopia- 
dora de color Canon, los siguientes artistas: el Equipo AC (J. R. Alcalá y F. Canales) que presentó la obra Rueda y homenaje al barroco, un ensamblaje de fotocopias Canon NP 400 monocolor de 1985; ambos eran los autores de un libro sobre electrografía y habían participado en la Bienal de Copy Art celebrada en Barcelona en 1985. Cejar con la obra Retrato electrográfico, una electrografía con Xerox System 125, rayos-x y fotocopiadora Canon realizada en París en 1985. Paco Rangel, autor autodidacta que trabajaba en Copenhague y premiado en la Bienal de COPE-Art. Barcelona de 1985, presentó Crucifixión, una impresión electrográfica mediante disolventes de 1985. Ricardo Cristóbal con Homenaje a Shwarzkogler, una fotografía procesada en Xerox con retoques sintéticos; Cristóbal había participado en la bienal de Sao Paulo 1977. Pere Noguera con Objetos. Obra Documento, una fotocopia tratada. Y Luisa Rojo, que participó, entre otras, con la obra Sombreros (1986), una fotocopia heliografiada y coloreada con aerógrafo sobre papel hialino, una especie de acetato.

En este trabajo se consolidaban varias de las aportaciones de Luisa Rojo a la fotografía experimental española: por un lado, la búsqueda de un lenguaje propio a partir de los procesos electrográficos de la imagen como obra única y basado, mayormente, en su fragmentación, acompañada por una huida de los colores primarios, que nunca le habían interesado demasiado, a favor de los colores "lavados". Y por otro, la presencia significativa de la imagen de la mujer, representada en esta ocasión con fotografías de gestos producidos bien en el rostro, bien en el cuerpo de gran tamaño, $120 \times 120 \mathrm{cms}$ y $2 \times 3$ metros. Con motivo de esta exposición se celebraría en casa de la artista una reunión con creadores próximos a la manipulación fotográfica y tecnológica. Muy poco tiempo después, la muestra itineraba a la galería Spectrum de Zaragoza, espacio donde Marisa González, expondría su obra un año más tarde.

De esta manera, Luisa Rojo prosigue su andadura por las rupturas y manipulaciones de las imágenes. Este mismo año produce la serie Cebras (1986). Se trata de un conjunto de fotografías sobre los pasos de cebra y la gente en movimiento. De entre todas ellas, me confiesa, hay una que aún le sigue fascinando, la que realizó en Arlés en 1983 (fig.1), y en la que puede verse de forma seriada y fragmentada la pierna andando de una mujer con la falda en movimiento. Esta fotografia analógica, al igual que el resto, fue realizada a partir de un negativo de 35 milímetros de blanco y negro. Seguidamente, la fotocopió en papel hialino y pintó con aerógrafo en los tonos lavados tan característicos de la artista.

Se trata de una imagen fundamental hasta la fecha de hoy, y convertida por la artista en recurrente en varios de sus montajes fotográficos: "La idea era ver una mujer decisiva, tirando para adelante y con energía. No fue mi intención poner una mujer coja ni desequilibrada" (ROJO, 2011). Insistir en este aspecto porque, tal y como me explica Luisa Rojo, en varias ocasiones se ha señalado que esta imagen era una especie de metáfora del desequilibrio.

El hecho de transformar radicalmente con la fotocopia el aspecto original de las imágenes de los pasos de cebra obedecía, claramente, a dos propósitos: primero, su ampliación hasta los casi dos metros exigía al espectador una mirada diferente de la obra; el público sólo podría identificar los fotogramas iniciales desde una distancia determinada. Segundo, satisfacía su espíritu más warholiano, a saber, su pasión por el grafismo y la estética del trazo. 


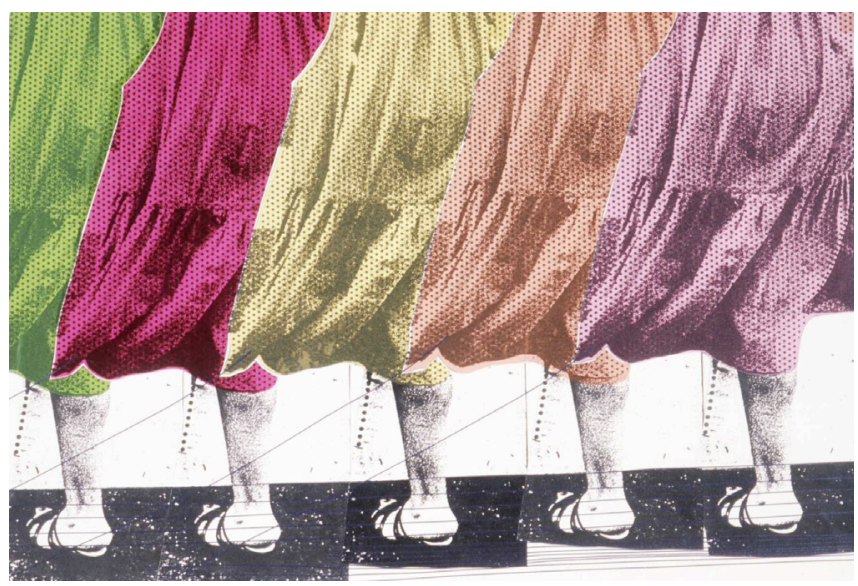

Figura 1. Pies. Serie Cebras, 1986. (cortesía de la artista)

Las ampliaciones, las fotocopias de tinta, las transferencias químicas, los papeles eran los elementos y materiales con los que habitualmente esta artista componía sus montajes. Tales instrumentos le permitían ampliar, con un coste sensiblemente reducido, los tamaños de sus trabajos hasta incluso más de 2 metros. Algo impensable si se tratara de una obra en papel baritado: "Si ampliaba en soporte fotográfico baritado me arruinaba y encontré contando lo mismo un procedimiento mas barato con un resultado y una textura que de otra manera no podía lograr. Tenía que jugar con la economía" (ROJO, 2011).

Como hemos visto hasta ahora, el trabajo experimental de Luisa Rojo propone una reflexión sobre la vida y la muerte, donde la mujer, a la que siempre ha defendido, empieza a cobrar un protagonismo vital. Concluye así, la que podríamos denominar como su etapa inicial en la que equilibra de forma magistral su interés por traspasar las limitaciones impuestas por las máquinas y los soportes con una obra, donde las repeticiones y el desdoblamiento de las imágenes inciden en su búsqueda personal de la expresividad -básicamente la fuerza gestual del rostro-, y en apurar la medida de la imagen. De esta manera, da paso a una segunda etapa que llega hasta nuestros días en la que consolida sus intereses iniciales bien conceptuales, prosigue con la fragmentación y manipulación de imágenes, como temáticos, la problemática del ser humano y la imagen representativa de la mujer, además de incluir en su repertorio bodegones y paisajes. De igual manera, asienta formalmente sus intereses estéticos: el gusto por La Bauhaus, el Arte Pop y el cine alemán de las décadas 50, 60 y 70.

La década de los noventa representa un trabajo constante con los hialinos, el aerógrafo y las fotocopias. No obstante, el inicio de la misma será importante, porque aborda nuevos propuestas gráficas como el sentido de la serie.

Su obsesión por el cine le lleva a emprender un trabajo, "Bolero a dos" (Sala Juana Francés, Zaragoza, 1990-1991), donde establece un paralelismo entre la era del Renacimiento y la década de los 90 a partir de dos mitos trágicos: Marilyn Monroe 
y Romy Schneider. La idea de la artista era realizar a estas dos mujeres suicidas una especie de funeral, "un canto a la vida, un reconocimiento" (ROJO, 2011). Para ello preparó una escenografía sobre la claraboya del techo de la galería, donde colocó fotocopias en blanco y negro sobre papel cebolla, y en medio de la sala trazó un círculo con cirios negros. La presencia del Arte Pop resultaba evidente no sólo por el motivo fotografiado, sino también por el modo de representarlo. Luisa Rojo interpretaba de forma muy singular la estética Pop al prescindir de la consabida planitud de la imagen e imprimirla de una narratividad sugerente y personal con la que invitaba al espectador a seguirla. Eduardo Momeñe (1990: 20-21) escribiría un interesante texto sobre la puesta en imagen de Luisa del que he extraído las siguientes líneas: “(...)Todo aquello que la fotografía representa no existe aisladamente. Los objetos hablan en su relación con otros, viviendo en un tiempo y en un espacio, e insertados en un contexto cultural que los define. Desde la visión fotográfica, aquella que los hace presentes pero que no les pone nombre, o por la mano que los apunta con el dedo aislándolos así de su contexto. Es la intención quien finalmente juega con la significación de las cosas".

La autora incluyó en sus fotografías una textura nueva, las rayas de las imágenes televisivas. La dificultad de este trabajo era básicamente técnica. Comenta que para hacer las fotografías de las imágenes que emitía el televisor tuvo que ayudarse de un trípode, además de utilizar distintas velocidades para evitar los clásicos barridos. Algunas de estas imágenes fueron tomadas a color en 35 milímetros para después ser pasadas, bien a Cibachromes o a un material similar de Fuji, bien directamente a papel de serigrafía, donde las tintas proporcionaban a los trazos de la imagen el punto importante de grafismo que buscaba la autora. Con este trabajo, la artista ahondaba en su preocupación histórica por los límites entre la abstracción y la figuración, así como por el trabajo en serie y la imagen repetida. La cualidad repetitiva de la fotocopia la encontraba ahora en la pantalla del televisor. Y de la misma manera que convirtió a la primera en soporte artístico, lo hará ahora con la segunda.

La televisión en sí misma, al igual que las imágenes mediáticas de las estrellas del cine que reproducen son convertidas en objetos fotografiables. No le interesa la imagen real de estos ídolos, sino la imagen que arroja de ellas la sociedad de masas y el medio que les consume, el televisor. En definitiva, se trababa de una profunda reflexión sobre el hombre y la actualidad contemporánea: "Pienso que estamos viviendo en una época que tiene conexiones estrechas con el Renacimiento, como en este periodo de la historia, en nuestro siglo, se están alumbrando y cuestionando problemas muy importantes. Las diferentes ciencias y también las artes adquieren un carácter global e interdisciplinar, los artistas están mantenidos hoy como ayer por los nuevos mecenas, los capitalistas y banqueros. Hoy también la clase privilegiada económicamente pretende diferenciarse por el gusto estético de poseer o coleccionar Arte, sino exterior de privilegio, mandan a los artistas organizar y diseñar sus fiestas y banquetes como sello que marca la diferencia. El parangón sigue estableciéndose, desaparece en el hombre el sentimiento de dar culto a lo divino y en el producto de la crisis y el cambio se manifiesta el culto a lo diabólico, a lo negro, a lo negativo, hace su entrada la magia negra, lo oculto. El fantasma de la peste -el Sida- hace su aparición amenazando y amedrentando al hombre del siglo XX" (ROJO, 1990). 
Por estas mismas fechas realiza un proyecto para la muestra "Nueve Fotógrafos Aragoneses de los 90" (fig.2) celebrada en el Museo Provincial de Zaragoza (1990) e itinerante por las ciudades de Huesca, Teruel y Pamplona. En la exposición participaron, además, Pedro Avellaned, Rafael Navarro, Gonzalo Bullón, Rafael Buisán, Ángel Carrera, Jacinto Esteban, Javier Inés y Antonio Uriel. Luisa expuso una serie de imágenes urbanas sobre la calle en las que se veía a individuos deslizándose por un pavimento fragmentado; metáfora, una vez más, de la fractura que vive el ser humano en el mundo contemporáneo. En esta ocasión se valió de un recurso puramente fotográfico, el picado, para sumergirse en la abstracción fotográfica deformando la imagen de la figura humana. Las fotografías en blanco y negro de los gestos y el movimiento de brazos y piernas de la gente caminando por el asfalto habían sido tomadas desde una ventana y montadas a modo de friso de $1 \times 2$ metros a partir del ras del suelo.

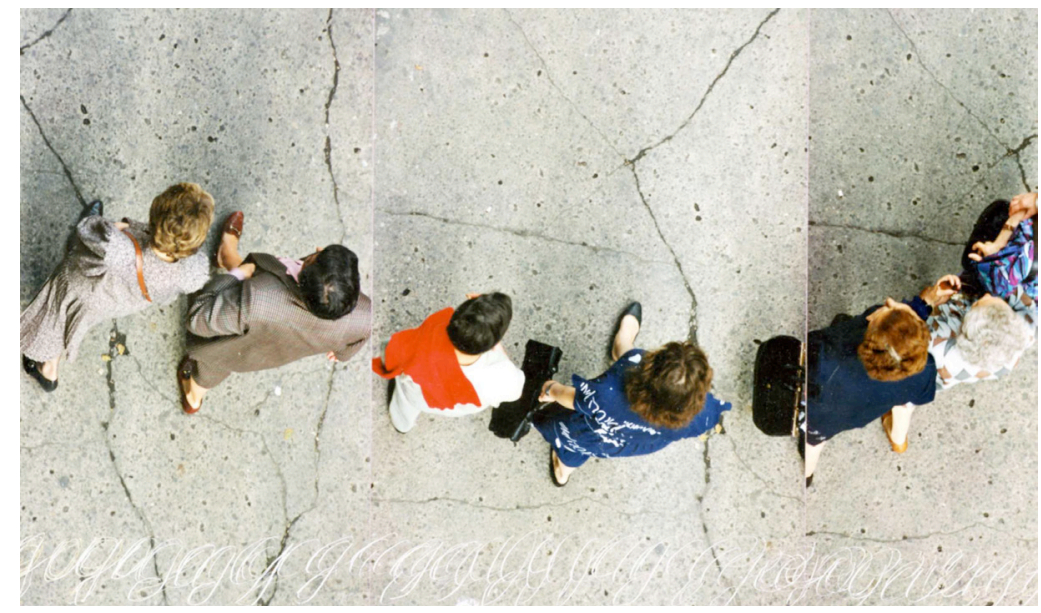

Figura 2. 2. 90, 1990. (cortesía de la artista)

En 1991, fue invitada por la Casa Polaroid para realizar el estilismo de sus nuevas películas color y placas blanco y negro. Recuerda de forma divertida la presentación que tuvo lugar en el Florida Park, y en la que llenó la fuente de la entrada con flores cortadas que iban cayendo. Me cuenta que vistió a dos modelos con un traje de torero y un mantón de Manila respectivamente, y que dispuso varios capotes en el interior del hotel, entre los cuales había instalado sus fotografías: una serie de sutiles bodegones y poéticos paisajes. Dos géneros, a partir de entonces, en los que posaría su mirada.

En este punto del uso de la Polaroid, una marca de lencería le encarga una serie de fotografías sobre torsos y espaldas femeninas, que utilizará como material de trabajo a partir del cual investigar acerca de la gestualidad del cuerpo femenino. Se trataba de una serie de Polaroids reproducidas en placas de 6x4,5 centímetros convertidas unas en Cibachromes de 60 y $80 \mathrm{cms}$, y otras en transferencias sobre papeles de grabado por vía de las tintas o de las gelatinas de las propias Polaroid. Expuso el trabajo en "I love you polaroid" (IV Bienal de Fotografía de Córdoba, 1991). Recientemente ha 
realizado con esta cámara un interesante documento sobre las fiestas tradicionales de Cetina titulado: La danza de la muerte (2011).

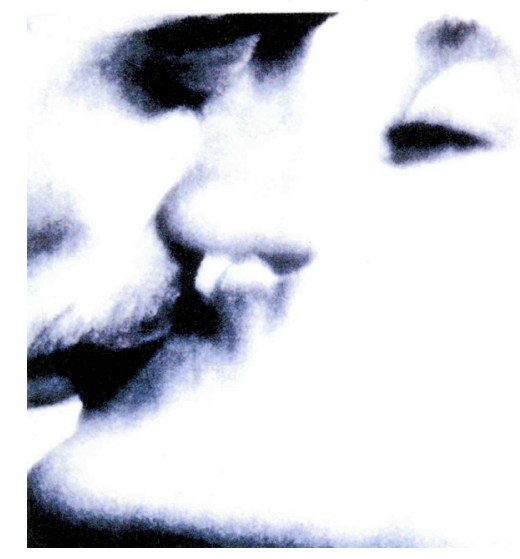

Figura 3. Beso. Serie Besos, 1992. (cortesía de la artista)

El trabajo con la lencería y el cuerpo femenino revelaba el interés de la autora por materializar las sensaciones. Un objetivo que culminó en la serie titulada Besos (1992, fig.3). A mi juicio, unos de los trabajos más interesantes y que mejor representan a esta artista.

Esta serie la formaban varias imágenes de cabezas humanas besándose, Cibachromes y Polaroid manipulados, donde el objetivo era mostrar la ruptura total de la imagen: "Quería el gesto, no el sexo" (ROJO, 2011). El hecho de recurrir a un formato grande obedecía, exclusivamente, al deseo de la autora de enfatizar la sensación del beso y de la luz, elemento fundamental en su creación: "Con la luz hago este arte de la fotografía que es el arte de las sensaciones y del sentir que radica principalmente en la intuición. La estética de la luz es la de la sensación sin filtros. La imagen, va desde un fragmento en el espacio, directamente al cerebro, sin filtros. Una superficie fotográfica es el espacio de un sueño que se ve y queda en el cerebro con la luz, gracias al sentido de la vista" (ROJO, 1998). Estas imágenes pudieron verse en Arco 93, en la galería Magda Belloti (Cádiz, 1993) y en la V Bienal de Córdoba (1993).

"Besos" representa la culminación del lenguaje multidisciplinar de Luisa Rojo. Un trabajo en el que las formas se disuelven definitivamente en una sinfonía de colores y de formas sutiles procesadas y alteradas mecánicamente por medio de la ampliación y la ruptura. El resultado no puede ser más inspirador. La fragmentación de estas cabezas cobran sentido en el mismo instante en que físicamente se funden sus bocas en un beso. En esta misma línea experimental acerca del gesto y la sensación, cabe mencionar otro trabajo sobre el rostro, Fragmentos (1992). Imágenes de gestos rotos y vueltos a unir. La ruptura es ya la fuente vital de la que emana, sin duda alguna, la fuerza técnica y expresiva de esta artista, que renace cuan ave fénix una y otra vez.

Si hay algo que destaca sobremanera en esta autora es, sin duda alguna, su ánimo de protesta que delata su condición de luchadora nata: "Casi siempre he protestado y hubo una fecha en la que protestaba por todo" (ROJO, 2011). En el Círculo de Bellas Artes de Madrid participó en "La crisis no existe", exposición celebrada en 1993 con 
motivo de la crisis económica acaecida en 1992. Llevó una serie sobre las esculturas de ranas de las fuentes de la Granja de San Ildefonso. Eran fotografias en las que las ranas aparecían bien con las bocas abiertas, las garras amenazantes o con sólo medio ojo. Y las mezcló todas en un gesto personal para, explica, "atrapar la protesta" (ROJO, 2011). El montaje fue espectacular y en consonancia con su protesta. Para ello colocó las fotocopias vegetales en blanco y negro y en color de las ranas y sus gestos delirantes sobre un ventanal traslúcido: "La fotografía es la luz, jugar con la luz con todo lo que eso significa y dice, que es mucho y eso te permite usar todos los soportes, que en este momento hay en el mercado, que también son muchos" (ROJO, 2011).

Con el mismo ánimo de protesta realiza la serie Claveles (1996, fig.4), presentada por vez primera en la galería Spectrum (1996): "Me vino a la cabeza la revolución y de ahí investigué el clavel como planta, cómo se llamaba, su nombre en latín que incluí en algunos fotogramas y empecé a mirar, a preguntar y descubrir que el clavel lo trajo a España Carlos V, cuando recibió en la frontera a Isabel de Portugal para casarse y se lo encargó a los navegantes que lo trajeron de Irak. El hecho de ir descubriendo todos estos nuevos datos me hizo reorientar el trabajo y monté en la Spectrum un mapa mundi fragmentado, donde se veía España y África en una pared de 3x6 metros con fotocopias de una atlas en blanco y negro y llené toda la pared. En el medio de ésta coloqué los claveles" (ROJO, 2011). Este trabajo fue expuesto posteriormente en "Metamorfosis de la Luz" (1998). Un proyecto subvencionado por la Embajada de España y resultado de una cooperación entre el Instituto Cervantes y la Sociedad Germano-Ibero-Americana de Schleswig-Holstein en el que también participaron: Pablo de Jevenois, Javier Vallhonrat y Juan Pedro Pérez Pardo. El Instituto de Lengua y Cultura Española de Hardenbergstrasse fue su primera sede durante los meses de abril y mayo.

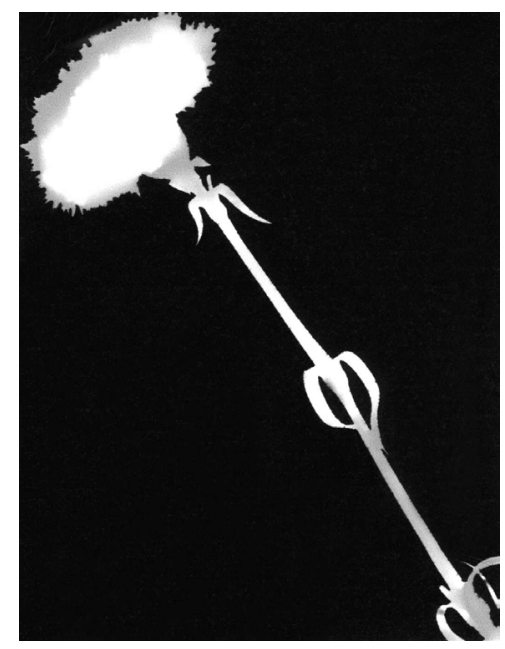

Figura 4. Clavel. Serie Claveles, 1996. (cortesía de la artista) 
Las mujeres han sido un tema de representación recurrente a lo largo de la historia del arte. En 1994, se celebra en la Fundación Telefónica de Madrid la muestra "Mujeres". Este fue un proyecto en el que únicamente participaron creadoras: Marga Clark, Ouka Leele, Ana Torralba, Montserrat Santamaría, Ana Casas, Marta Povo, Isabel Muñoz, Rosa Muñoz y Luisa Rojo. Estuvo comisariado por Rosa Olivares. Pretendía mostrar un cambio de signo en la imagen femenina, mayormente construida y definida por la mirada masculina. Luisa Rojo presentó la serie Niñas (1994). Un conjunto de cinco espléndidos retratos con los que se representaba a la mujer durante la etapa de la crianza. Esta fue contemplada desde el nacimiento, con la imagen de un bebé durmiendo plácidamente, seguida de la infancia con el rostro sonriente de una niña de dos años, hasta llegar a la adolescencia más incipiente con el bellísimo y enigmático rostro de Niña pintada (fig.5). Sus fotografías se convirtieron en sensaciones propias de esta etapa; el tiempo en el cual se transmite la esencia de la vida. Y vida era, precisamente, lo que se sentía al contemplar sus fotografías. Lo cual resulta igualmente reconocible en el abanico personal, y vitalista que componen el resto de sus propuestas creativas con las que nos sumerge en todo lo importante que la vida representa.

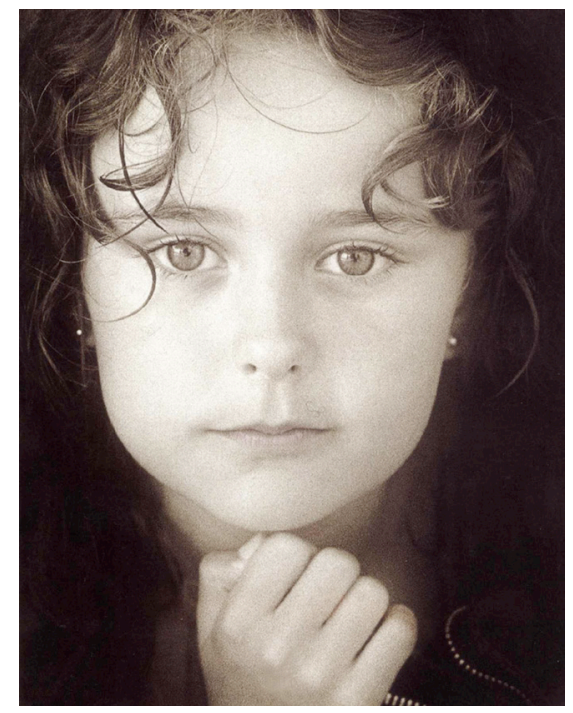

Figura 5. Niña pintada. Serie Niñas, 1994. (cortesía de la artista)

Se inicia aquí una larga etapa en la que la exploración del tema femenino se convertirá en una constante. En 1996 realiza la obra ¿Para quien Europa? (fig.6). Se trata de una relectura de la obra de Pedro Pablo Rubens "El rapto de Europa" (16281629). Un trabajo en el que la fotocopia y la fotografía se funden en una espiral de sugerencia visual del mundo femenino. La imagen pudo verse años más tarde en "Mujeres. Mujeres. Miradas de mujer. Mujeres miradas" (Fundación Caja Castellón, 2003). Una exposición que, explicaba su comisaria Martine Soria, quería recordar que las mujeres existen también por la mirada de los otros. 


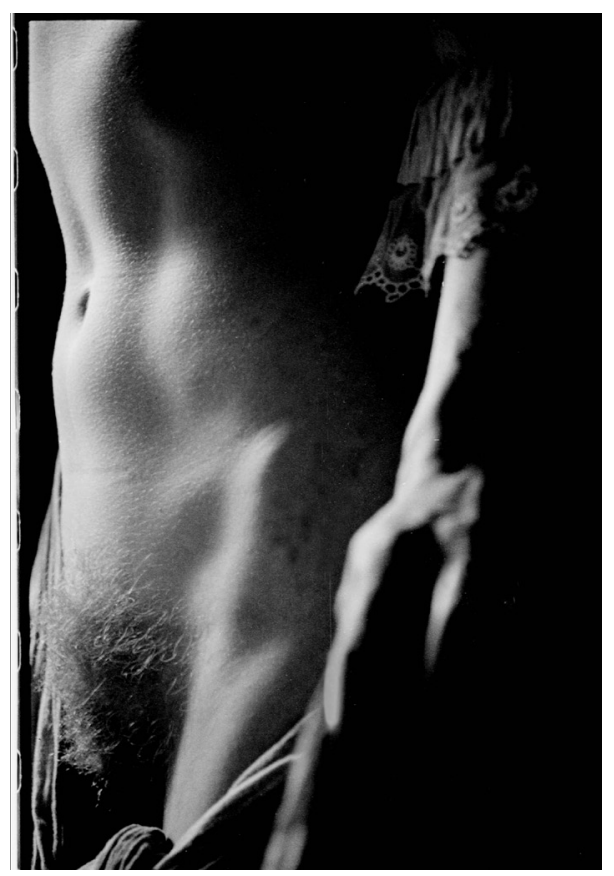

Figura 6. Para quien Europa. Serie Rapto de Europa, 1996. (cortesía de la artista)

"Memorial Book" (1998) fue una iniciativa común del Instituto de la Mujer y la Asociación Cultural Stanpa organizada por la Fundació Cultural de La Caixa de Terrassa en torno a las relaciones entre el libro y las diferentes consecuencias artísticas que de el extraían veintiuna artistas: Sonia Abraín, Ana Aragüés, Eva Armisén, Serafina Balasch, Pilar Catalán, Pilar Dolz, Isabel Fernández, Elvira Fustero, Ana Ñandú, Sara García, María Cristina Gil, Concha Jerez, Maribel Loren, Pilar Moré, Paloma Navares, Silvia Pagliano, Ana Pérez, Teresa Ramón y Pilar Viviente. El proyecto, al igual que lo había hecho antes "Mujeres", quería acentuar el papel de la mujer, en este caso como transmisora y nexo de lenguajes. Todas ellas entablaron una relación personal con el carácter táctil y visual de los libros, transformándolos en objetos artísticos únicos o en pequeñas instalaciones. Luisa escribía el siguiente texto al hilo de su imagen formulada a través de la luz y la poesía: "Pienso, creo que: la luz crea espacio, la luz en sí misma tiene vida, por su magia podemos transfigurar lo ordinario en sublime, el arte de la creación con la luz es eminentemente objetivo/ descriptivo. El arte de la luz es una fuente inagotable de creación. Las fotografías son superficies en el espacio de un mundo que continúa en todas las direcciones, más allá de los límites de las imágenes" (ROJO, 1998). La muestra contó con la conferencia inaugural de la escritora Magdalena Lasala.

Difícilmente podemos encontrar en la actualidad artistas que produzcan obra única. Luisa Rojo es una de ellas. Esta particularidad, hoy en día excepcionalidad, explica su pasión por el Cibachrome. Confiesa que, en parte, se debe a su permanencia: el proceso químico realizado con productos minerales hace que la emulsión sea mucho 
más permanente, y que la imagen permanezca inalterable, incluso, sin marco. Es un soporte que ha intervenido mayormente y al que ha llegado a desprenderle parte de su emulsión por vía de la intervención directa con un cúter sobre el papel plástico. En consecuencia, su obra tiene un aspecto experimental muy marcado. Cualquier objeto, proceso, técnica, material es susceptible de ser manipulado: "Me encantan las manipulaciones antes de hacer la toma o después. Con ellas es como más a gusto me siento... una manipulación en la que el color se ha alterado, otras en las que el trazo final se ha convertido en una trazo corto. La manipulación aplicada en distintos soportes. A gusto me encuentro cuando logro sacar en plano lo que tengo, la sensación, la sinestesia, en la cabeza y en la química... cuando consigo sacar eso, ¡ay! Digo, esto era" (ROJO, 2011).

No es extraño, por tanto, las múltiples uniones entre materiales "tocables" y baratos con otros de carácter "noble" y permanente como el Cibracrome. La serie Comida (2001, fig.7) es prueba de ello. Este trabajo, al igual que Claveles, fue otra serie protesta, pero también un reconocimiento del papel de la mujer. Esta vez por la falta de alimento en el mundo: "Me gusta plasmar aspectos de la vida. He llegado a esto por lo que hay en la prensa, por lo que nos rodea, por protestar contra algo que está tapado por otras cuestiones menores y que es uno de los lados tristes de estos principios del siglo XXI. Todos teníamos que ponernos serios ante este tema" (ROJO, 2011).

El punto de partida para esta nueva serie fue un texto que escribió tiempo atrás: "COMIDA, NO QUIERO CERA, QUIERO COMIDA, NO QUIERO CERA, QUIERO COMIDA, NO QUIERO CERA, QUIERO COMIDA, NO QUIERO CERA, CERA, PARAFINA, SUSTANCIA SÓLIDA Y BLANCA FUSIBLE, QUE SE OBTIENE DESTILANDO PETRÓLEO O MATERIAS BITUMINOSAS NATURALES, CERA, SUSTANCIA SÓLIDA Y BLANCA SEGREGADA POR LAS ABEJAS PARA CONSTRUIR LAS CELDILLAS DE LOS PANALES, ABEJA, INSECTO..." (ROJO, 2001).

El proyecto fue concebido como una instalación contenedora de: fotografías convencionales de los años 40 y 50 compradas en el Rastro y Polaroids manipuladas; fotografías de penumbra, penuria y hambruna tomadas de la pantalla del televisor que reflejaban el horror de los cuerpos, casi sin vida de los prisioneros en los campos de concentración; fotocopias tratadas, textos cargados de mensajes y sugerencias de ruego y protesta; manos de cera y exvotos, que aún se encuentran en las iglesias, comprados en la calle Toledo, y objetos varios como vasos, tejidos, parafina, alfileres, papel hecho a mano, espejos, cintas y comestibles como garbanzos y aceite.

La sinestesia jugaría aquí un papel fundamental, porque Comida debía conmover nuestros sentidos. Para sugerir la penuria recurrió a la imagen de una mujer con niño construida a base de cristales: "Una especie de mujer traslúcida. Lo hice con cristales y fotografié la composición que debía sugerir un cuerpo femenino. Cristales para dar fragilidad, cuando no se tienen posibilidades" (ROJO, 2011). Por otro lado, los desnudos femeninos dulcificaban el conjunto, y las imágenes cálidas de color sepia transmitían la impotencia y el dolor padecido por la mujer al no tener nada que dar de comer a sus hijos. 


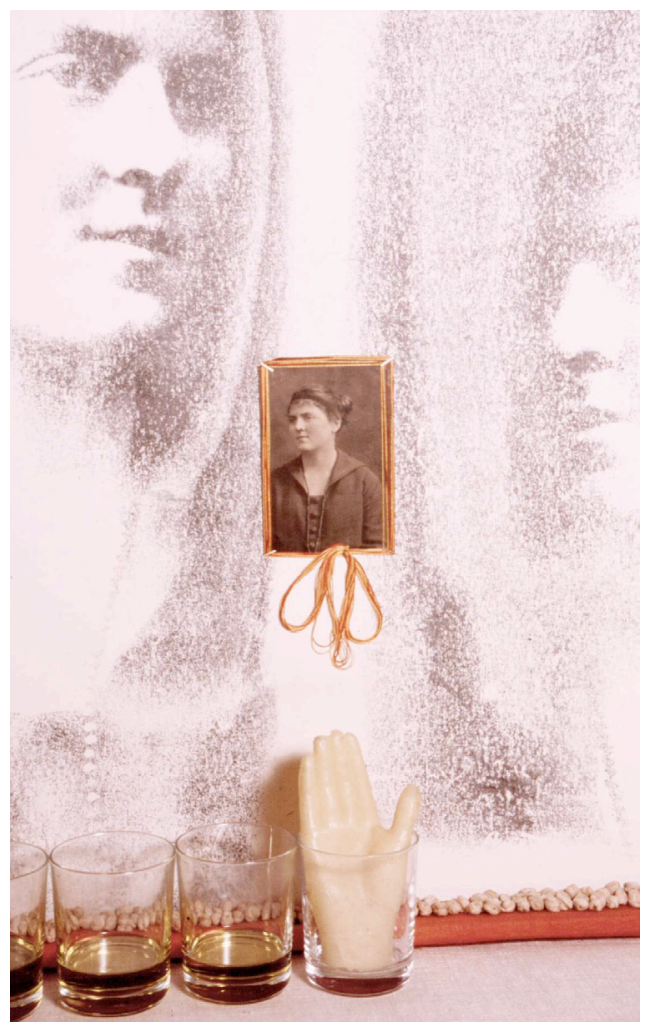

Figura 7. Comida. Serie Comida, 2001. (cortesía de la artista)

Tras este trabajo, la autora continúa preocupada por el entorno que impide al individuo gozar de libertad. Alas rotas (2002, fig.8) incide sobre este concepto. Partiendo de unas plumas desarrolla un trabajo a base de series fotográficas, recordatorias del Arte Pop, que evocan la fragmentación y ruptura del ser humano: “(...)Si alguien tiene fortaleza puede tirar hacia delante, pero si le han cortado las alas en la etapa de la crianza, le han arrebatado todo aquello que tiene que tener el ser humano, inteligencia, intención. Todo aquello que dan los sentimientos y que proporciona estabilidad y fuerza. Por eso vive con miedo, encogido, no se atreve a hablar... Esto era Alas rotas" (ROJO, 2011). Las plumas fueron fotografiadas en una combinatoria infinita, manipuladas, retocadas y ampliadas hasta $2 \times 2$ metros para inspirar, además de un ritmo seriado la sensación de movimiento y libertad. A lo que se sumaron los colores que, aún velados, recordaban la bandera republicana, y un texto manuscrito sobre los acetatos que recubrían la imagen digital y atrapaban algunas plumas reales.

La serie fue presentada en la sala de exposiciones del Ayuntamiento de Boltaña, con motivo de la primera edición del Festival Fotográfico Huesca Imagen. El resultado fue un conjunto fotográfico en el que todo quedaba perfectamente integrado. Un paso más de la artista en la consecución fotográfica de la experiencia sensible a partir de un material de trabajo extraído de la vida y los sentimientos. 


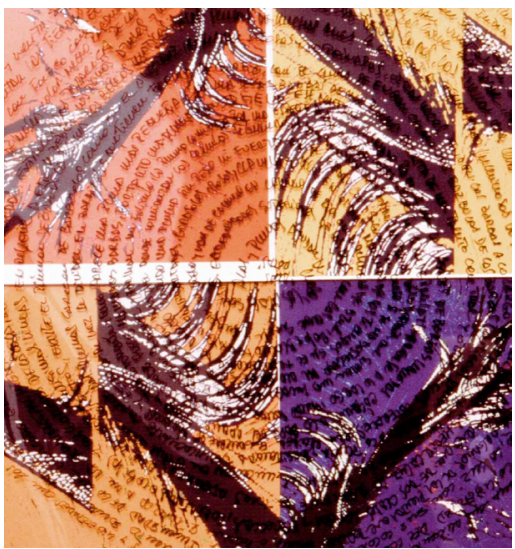

Figura 8. Serie Alas rotas, 2002. (cortesía de la artista)

La trayectoria artística de Luisa Rojo revela un viaje infinito que le lleva de la imagen a la fragmentación de forma cíclica. "Péiname, despéiname" (2003, fig. 9), un trabajo que pudo verse en la edición de Entrefotos 03, es una prueba más de esta espiral. Aquí retorna a la fragmentación con fotografías, algunas de ellas fueron tomadas de las mujeres que aparecían retratadas en las obras del Museo del Prado. Fotografías de rostros, gestos y cuerpos para suscitar la sensación de tocar: "La idea que va implícita en el título del trabajo era que la gente viera el sentido del tacto a través del gesto que nos lleva a tocarnos el cabello" (ROJO, 2011).

Y de nuevo el montaje, sumamente cuidado, plantea fotografías e instalaciones con objetos relativos al cabello y varios fotogramas realizados con coletas directamente. Para su realización colgó fotografías en una caja de metacrilato, a modo de tocador, y la llenó de objetos propios del pelo pasadores, horquillas, peinetas. Todo ello acompañado de un texto de Séneca extraído de la obra De la brevedad de la vida (55 d.C.), incluida en su obra Diálogos.

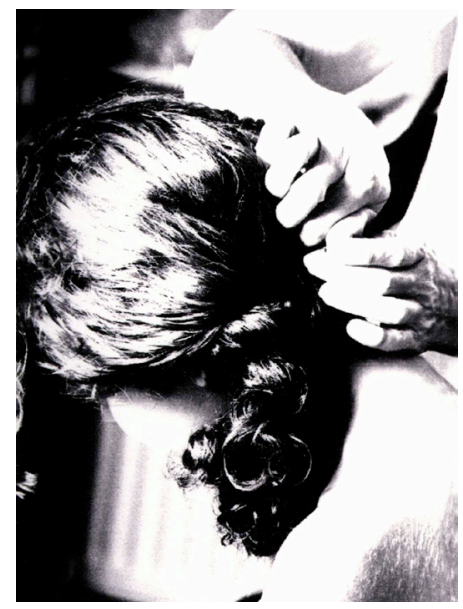

Figura 9. Péiname. Serie Péiname, despéiname, 2003. (cortesía de la artista) 
Otra de sus protestas fue contra la Iglesia. La tituló "Quitapesares" (2007, fig.10). Este trabajo giró en torno a la imagen del dios romano Mitra, dios de la luz solar, "para que no me cerraran la exposición" (ROJO, 2011), me explica riendo. El título, no exento de sorna, hacía referencia a la expresión andaluza empleada para describir el consuelo o alivio por la pena. Esta fue su manera de protestar contra la institución eclesiástica. La artista realizó una serie de composiciones y collages digitales reproducidos en giclée con imágenes de mitras y procesiones.

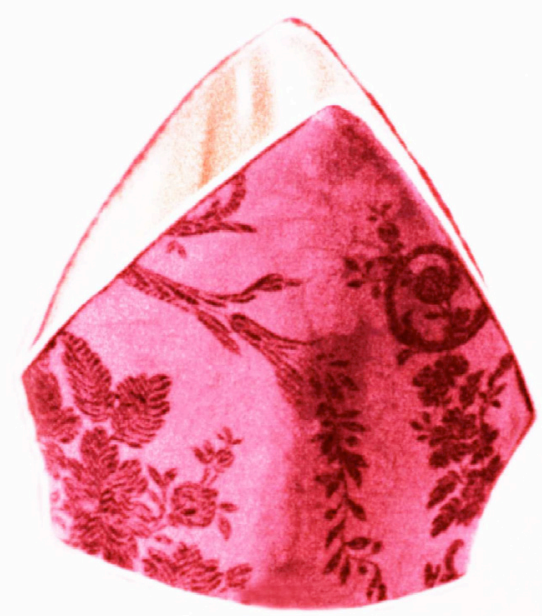

Figura 10. Mitra. Serie Quitapesares, 2007. (cortesía de la artista)

A finales de 2009, Luisa Rojo va a ser el alma máter junto a Marie G. Alquier y yo misma del proyecto colectivo titulado "Patata $21+1$ ", que pudo verse en la Galería Rafael Pérez Hernando (2008-2009) y en el Palacio de la Merced (Córdoba, 2010). Fue proyectado y realizado para visibilizar en el mundo del arte la declaración de la ONU del 2008 como Año Internacional de la Patata. $21+1$ artista contemporáneos planteaban la relación que existe entre la realidad objetiva de la patata y la percepción emocional del objeto en sí mismo. Un objeto donde el espacio y el tiempo se fundían en la raíz de la intuición. Luisa Rojo presentaba una fotografía, que una vez más aludía al gesto: una patata partida por el centro por un cuchillo, que representaba las variopintas amenazas que habitan en nuestra la ciudad.

Recientemente ha colaborado en el proyecto "Mujeres. Doce Fotógrafas" (Spectrum Sotos, Zaragoza, 2012). Una exposición sobre las mujeres de mediana edad invisibles para la mayor parte de la gente, y sin embargo, muy presentes en todos los ámbitos de la vida. Esta muestra se ha organizado a partir de la reciente publicación del libro de Margarita Barbáchano, Mujeres en la edad invisible. Su participación ratifica una vez más el espíritu innovador de esta artista, gestado como vimos en las décadas setenta y ochenta, con el que abanderó una corriente creativa y experimental, que confiaba plenamente en la fotografía como una disciplina artística independiente y multidisciplinar. 


\section{Conclusiones}

Indiscutiblemente, el trabajo de Luisa Rojo resulta fundamental, al igual que enriquecedor, para la historia y el lenguaje de la fotografía española. Sus aportaciones al respecto ponen de manifiesto su capacidad para alcanzar un estilo artístico de extraordinaria personalidad, que refleja la constante voluntad de la artista por encontrar a través de la vía experimental nuevas formas gráficas de expresión con las que interpretar con ironía y crítica la naturaleza cambiante del mundo que le rodea. Pero también, porque este proceso de observación lo concibe como multidisciplinar, teniendo cabida, igualmente, tanto las nuevas tecnologías, como la pintura, la cerámica, el grabado, etc. En consecuencia, podemos afirmar que la obra de Luisa Rojo representa una obra de gran valor inscrita en la corriente de la fotografía experimental, una tendencia en la que han trabajado otras grandes artistas como Marisa González, igualmente pionera en el uso de las nuevas tecnologías y sistemas generativos.

Resulta habitual encontrar a Luisa Rojo trabajando al mismo tiempo en dos obsesiones, ideas en realidad, que no desaparecen hasta que las desarrolla y materializa. En este proceso, como ya hemos visto, la inclusión de objetos, textos, papeles, etc. contribuyen a eliminar cualquier tipo de limitación o restricciones a la expresividad. E igualmente, refuerzan el mensaje con múltiples sugerencias. El uso de la técnica es muy importante en su trabajo, pero tiene muy claro que ésta nunca debe subordinar a la expresión. Tampoco, los clásicos formatos del papel fotográfico. Artista de la galería Spectrum de Zaragoza desde su fundación, confiesa, que este espacio abierto para exponer vanguardia fotográfica nunca le ha cuestionado nada de lo que ha presentado, ni tampoco cómo lo ha presentado.

A lo largo de su trayectoria, ha desarrollado una obra unitaria, coherente e innovadora, siempre respetuosa con la técnica, el soporte y por la fotografía en sí misma, centrada en el análisis de las transformaciones de los procesos de reproducción de la imagen. Sus propuestas creativas plantean problemas que afectan al hombre y a la sociedad contemporánea.

La particularidad de su estilo, esencialmente vitalista, reside en el modo en que nos sumerge instintivamente en el campo de la abstracción, y articula la sinergia entre técnica y expresión y arte y sociedad. De la misma manera, lleva a cabo una investigación formal, que transgrede los límites de la fotografía tradicional, e interpreta al mismo nivel forma y contenido. Sobre ambos, la fotocopia y el color interactúan, recalando, una y otra vez, en el sentido crítico e irónico de la repetición variada de la imagen única. Cabe señalar su habilidad para transformar a las imágenes en objetos reversibles.

En la actualidad, su trabajo no ha perdido un ápice de aquel deseo inicial por experimentar y manipular con la imagen fundamentado en el arte gráfico de los años 70 y 80 , y evoluciona con los actuales medios digitales como las impresoras y los escáneres, con los que fabrica imágenes directamente. Sus fotografías hablan por ella misma: "He tratado de decir lo que quería decir con lo que tenía en el bolsillo. El resultado a lo mejor me llevaba a una cosa un poco extrema o a veces escasa, pero le daba las vueltas necesarias para lograr el resultado que quería" (ROJO, 2011).

Vanguardista y ecléctica a partes iguales continúa cimentando su trabajo en la libertad más absoluta. La selección inusualmente sugestiva y expresiva de medios, 
técnicas y estilos avalan un enorme potencial creativo. El profundo deseo por la experimentación y el atrevimiento artístico por vía del mestizaje armonizan con la función y los medios con los que elabora el arte, y cuestiona el significado de las imágenes. Así es Luisa Rojo. Una inventora de historias que con amor nos recuerda, pese a todo, que vivimos en un mundo que puede ser maravilloso. Un mundo donde el arte debe alcanzar la cotidianeidad y los sentimientos.

\section{Glosario}

Cibachrome: se introduce en España en la década de los 80. Es un procedimiento de obtención de copias positivas en color a partir de diapositivas o transparencias. Se trata de un papel tratado de larga duración con una emulsión de colorantes que aparecen en la imagen final. El resultado es una saturación de colores.

Copy Art: es un movimiento desarrollado durante la década de los sesenta y vinculado al Arte Pop y al binomio arte y sociología. El atractivo de la técnica de la electrografía -en EE.UU Copy Art y en España arte de la fotocopia- radicaba en su capacidad para reproducir de forma barata, rápida e infinita una imagen. Se presentó como técnica donde los límites de la innovación y la experimentación quedaban establecidos por la tecnología y materiales aplicados que ponían el arte al alcance de todos los públicos.

Electrografía: Marisa González denomina Electrografía a los trabajos realizados con ciertos instrumentos para la comunicación llevados al terreno del arte, con el uso de la fotocopiadora como base del proceso creativo. En Europa, Estados Unidos y Canadá, el movimiento comenzó en los años 70: los artistas, atraídos por la inmediatez y los bajos costes de la manipulación electrográfica, la usaron en un principio como un recurso rompedor y desmitificador del Gran Arte, surgiendo la denominación de Copy Art. En esa década hubo en España alguna exposición individual y aislada de gran interés. Fueron varios los artistas que, deslumbrados por el nuevo medio y la fragilidad del soporte, se adentraron a experimentar con las fotocopiadoras: unos como propuesta rompedora; otros con una actitud de investigación ante este nuevo medio, utilizándolo no sólo como una herramienta de reproducción, sino a la búsqueda de su lenguaje propio.

Giclée: proceso que permite hacer impresiones artísticas desde una fuente digitalizada utilizando una impresora de chorro de tinta a partir de fotografías analógicas. Las imágenes generadas por cámaras fotográficas, escáneres de alta resolución o programas de diseño e imagen digital son impresas con tintas de calidad sobre papel $100 \%$ fibra de algodón. Este proceso permite una reproducción de mayor precisión de color respecto a otros métodos de impresión. 


\section{Referencias}

Azpeitia, P. (2001, 22 de noviembre). .Luisa Rojo. Heraldo de Aragón, Cultura Espectáculos, p. 42.

Álvarez Sotos, J. J. (1990). Luisa Rojo, Bolero a dos. Zaragoza, Sala Juana Francés pp. 4-5.

Barbáchano, M. (2011). Mujeres en la edad invisible. Zaragoza, Mira Editores, S.A. Colección Sueños de Tinta, ${ }^{\circ}$ 17, pp. 96-97.

Calvo Serraller, F. (1992). Enciclopedia del arte español del siglo XX, Madrid, Mondadori, Volumen 2, p. 401.

Campos, L. (1986, 31 de mayo). Luisa Rojo, imágenes con nueva tecnología. El día Zaragoza, p. 40.

Cañas, G. (1984, 2 de enero). La escasez de tecnología apropiada dificulta la extensión del copy art en España. El País, La Cultura, p. 41.

Carabias Álvaro, M. (2010). Palpable. Patata 21+1. Córdoba, Fundación Provincial de Artes Plásticas Rafael Botí-Diputación de Córdoba, p.12.

Fité, A. (2002, 7 de julio). Huesca Imagen incita a la reflexión. Heraldo de Aragón, p. 40.

González, M. (s.f.). Electrografia. Consultado el 12 de enero de 2012, de http://www meiac.es/net-spain/media.php?media $=2$

Gonzalo Les, P. (2009). La sala Juana Francés y su apoyo a la mujer artista. Artigrama, núm. 24, pp. 685-700.

Ibares, A. (1990, 15 de diciembre). Marilyn y Romy, en Bolero a dos. Dos mujeres míticas, tema para las fotografias de Luisa Rojo. El día. Zaragoza, p. 39.

López, H. (1990, 20 de diciembre). Juana Francés. Luisa Rojo. Heraldo de Aragón, Zaragoza, p. 40.

María Luisa Rojo Gayán (s.f.). Consultado el 20 de noviembre de 2011, Aragón, página web de GEA. Gran Enciclopedia Aragonesa Online: http://www enciclopedia-aragonesa.com/

Marín Medina, J. (1994, 1 de diciembre). La construcción de otra imagen. ABC de las Artes, p.35.

Marina, M. (1984, 15 de marzo). Spectrum. Luisa Rojo y Pablo Márquez. Heraldo de Aragón, Zaragoza, p. 42.

Márquez, P. (1993). Luisa Rojo: la alegría de vivir. Luisa Rojo. Besos. Córdoba, Serie Fotógrafos en la Posada del Potro Posada del Potro, Ayuntamiento de Córdoba, p. 4.

Márquez, P. (1984). M-30. Madrid, Galería Moriarty.

Molinero, A. (1990). La fotografía aragonesa, aquí y ahora. FV, no 25, pp. 90 y 92.

Momeñe, E. (1990). Luisa Rojo. Bolero a dos. Sala Juana Francés, Zaragoza, pp. 20-21.

Olivares, R. (2008). 100 Fotógrafos españoles. Madrid, Exit, pp. 342-346.

Olivares, R. (1994). Mujeres. 10 Fotógrafas / 50 Retratos. Madrid, Publicaciones de Estética y Pensamiento, pp. 35.

P,S. (2001, 31 de octubre). Luisa Rojo protesta con imágenes contra la hambruna Heraldo de Aragón, Cultura/Espectáculos, p. 44. 
Rojo, L \& Moré, M. (1999). María Luisa Rojo: diciembre 1999-enero 2000. Madrid, Galería de Arte May Moré.

Rojo, L. (1994). Arte Fotográfico, na 500, p. 80.

Rojo, L. (1998). Memorial Book. Terrassa, Centre Cultural Caixa de Terrassa. Sanz, J.C. (1985). El lenguaje del color ( $1^{\mathrm{a}}$ ed.). Madrid, H. Blume, p. 13. Soria, M. (2003). Mujeres Miradas de Mujer-mujeres. Mujeres Miradas. Castellón, Bancaja, Fundación Caja, pp. 8, 62 y 77-78. Vázquez, J. (1990). ¿Quién mató a las estrellas del POP?, Luisa Rojo, Bolero a dos. Zaragoza, Sala Juana Francés, pp. 6-7.

Villarrocha, V. (1990, 22 de diciembre). La imagen latente. El Día, Zaragoza, p. 38.

\section{Exposiciones}

M-30. Galería Moriarty, Madrid, 1983.

Cinco fotógrafos del color. Galería F. de Atenas, Grecia, 1984.

Procesos. Cultura y Nuevas Tecnologías. MNACRS, 1986.

Nueve Fotógrafos Aragoneses de los 90. Museo Provincial de Zaragoza, 1990.

Bolero a dos. Sala Juana Francés, Zaragoza, 1990-1991.

I love you polaroid. IV Bienal de Fotografía de Córdoba, 1991.

Besos. Arco 93, galería Magda Belloti (Cádiz, 1993) y V Bienal de Córdoba (1993). Mujeres. Fundación Telefónica de Madrid, 1994.

Claveles. Galería Spectrum, Zaragoza, 1996.

Memorial Book. Fundació Cultural de La Caixa de Terrassa,1998

Comida. Galería Spectrum, Zaragoza, 2001

Alas rotas. Huesca Imagen, 2002

Péiname, despéiname. Entrefotos 03, Madrid, 2003.

Mujeres. Miradas de mujer. Mujeres miradas. Fundación Caja Castellón, 2003.

Quitapesares. Galería Spectrum, Zaragoza, 2007.

Patata 21+1. Galería Rafael Pérez Hernando, Madrid 2008-2009 y Palacio de la Merced Córdoba, 2010.

Mujeres. Doce Fotógrafas. Spectrum Sotos, Zaragoza, 2012. 